\title{
LEGITIMACIÓN Y CONSENSO EN LA IUSFILOSOFÍA ARGENTINA
}

\section{Introducción}

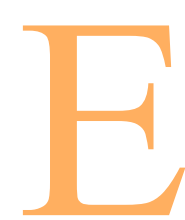

n 1956, Carlos Cossio ${ }^{1}$, director del Instituto de filosofía del derecho de la Facultad de Derecho y Ciencias Sociales de la Universidad de Buenos Aires, fue destituido por Ambrosio L. Gioja, en otros tiempos uno de sus más destacados discípulos. Este acontecimiento señalaba la contrapartida institucional de un cambio político de gran trascendencia para nuestro país: el golpe de Estado de la «Revolución Libertadora» que terminó con el régimen peronista.

De este modo, comenzaba la lenta desaparición de la teoría egológica del derecho ${ }^{2}$ que Cossio había comenzado a desarrollar a partir de 1941 y que había alcanzado su apogeo durante el peronismo, transformándose en la forma predominante de la iusfilosofía argentina ${ }^{3}$.

A. Gioja, luego de haber expulsado a Cossio de la Universidad, dio un nuevo impulso al Instituto ocupándose de enseñar la obra de Hans Kelsen. Esta decisión provoca una notable disminución de la influencia de la egología. A. Gioja, de marcados sentimientos antiperonistas, desterraba definitivamente una teoría que mantenía importantes coincidencias con el peronismo.

\footnotetext{
${ }^{1}$ Carlos Cossio ha sido el iusfilósofo de mayor influencia en la Argentina. Autor de numerosos libros, entre los que se destacan, El concepto puro de la revolución, Barcelona, Bosch, 1936; La plenitud del ordenamiento jurídico, Buenos Aires, Losada, 1936; La valoración jurídica y la ciencia del derecho, Buenos Aires, Losada, 1944. Su figura intelectual fue de excepcional importancia para el desarrollo de la moderna escuela argentina de filosofía del derecho.

${ }^{2}$ Egología es el nombre de esta teoría jurídica. En términos generales, esta concepción sostiene que la norma de una conducta humana es un concepto que a través del proceso jurídico termina por integrar esa conducta. Por lo tanto, la conducta humana es el verdadero objeto del conocimiento jurídico. Vid. COSSIO, Carlos, La teoría egológica. Buenos Aires, Losada, 1944.

${ }^{3} \mathrm{Su}$ influencia no se restringió a la Argentina sino que se extendió al campo cultural latinoamericano. Aún en nuestros días, en Brasil la iusfilosofía se muestra receptiva de la egología. Posiblemente por influencia de Antonio Machado Neto, representante de la egología en ese país. Vid. ATIENZA, Manuel, La filosofía del derecho argentina actual. Buenos Aires, De Palma, 1984, pág. 33.
} 
Gioja se interesaba por la fenomenología de E. Husserl y la teoría pura kelseniana pero también contribuyó al desarrollo de los primeros estudios de filosofía analítica en el país. Hacia 1960, propiciada por C. Alchourrón, E. Rabossi, Genaro Carrió y Roberto Vernengo comenzaban a tener cada vez mayor relieve los estudios de la iusfilosofía analítica.

La preocupación de Gioja por desterrar la egología de los estudios iusfilosóficos daba cuenta de la fuerte relación existente entre filosofía del derecho y Estado de derecho. En este sentido, nuestro trabajo pretende estudiar esa relación usando como terreno de ilustración la propia obra de A. Gioja. Autor que intentó construir una iusfilosofía con derivaciones políticas democráticas.

\section{Axiología jurídica}

Una de las principales dificultades concernientes al estudio de la obra de A. Gioja ${ }^{4}$ está referida a la importancia que el magisterio oral adquirió en su trabajo teórico ${ }^{5}$. La notable influencia del legado de Gioja se debe, sin lugar a dudas, a este formidable magisterio. Su obra apenas condensa su pensamiento resumido en casi una treintena de artículos, algunas conferencias y notas personales. Sin lugar a dudas, otro problema no menos grave resulta de la discontinuidad y asistematicidad con que trata ciertos temas de la filosofía del derecho.

Sin embargo, un análisis que intente superar estos obstáculos, sistematizando la estructura general de su obra, seguramente revelaría que la misma encierra como uno de sus potenciales más ricos la intención de construir una ontología jurídica que logre explicar axiológicamente la naturaleza de su objeto.

$\mathrm{Su}$ proyección teórica se inclina por el análisis de la problemática jurídica, entendiendo por ésta, la normatividad social del comportamiento humano. El estudio se desarrolla mediante la constitución de estructuras teóricas que permitan la objetivación de las conductas humanas, y a su vez, la construcción de una axiología que pueda dar cuenta del comportamiento de ese objeto y de las estructuras objetivantes que realizan su descripción.

Un proyecto teórico de este perfil filosófico implica desarrollar una teoría de valores que acompañe la discusión de las cuestiones ontológicas.

\footnotetext{
${ }^{4}$ Ambrosio L. Gioja (1912-1971) puede ser considerado, junto a C. Cossio y Sebastián Soler, uno de los principales fundadores de la moderna escuela argentina de filosofía del derecho. Supensamiento reconoció como influencia determinante las obras de I. Kant, E. Husserl y H. Kelsen.

${ }^{5}$ Sobre el punto, dicho magisterio ha sido quizás más importante y fecundo que su obra escrita.
} 
En este sentido, un desarrollo filosófico de este alcance reclama una metodología que tome a la propia experiencia como punto de partida privilegiado a la hora de describir los actos de conciencia, sus contenidos objetivos al momento de la valoración frente a determinadas conductas.

Esta concepción ontológica del derecho y la elección metodológica que la acompaña puede percibirse ya en los primeros textos de Gioja. Desde su primer trabajo de importancia se revela este proyecto filosófico ${ }^{6}$ de largo aliento.

La aspiración central de sus escritos más destacados se resuelve en la construcción de una filosofía jurídica que desarrolle una adecuada teoría de aquellos valores que operan en el terreno de las prácticas jurídicas?.

De hecho, para este autor, es correcto definir la normatividad a partir del establecimiento de juicios que fijan la relación especial que se evidencia entre una conducta humana y un valor. Precisamente, la evidencia es el acto de conciencia fundante del valor y el resultado de la intuición que reconoce y aprehende el valor que le es dado al individuo. Dicha evidencia es el criterio de verificación valorativa ${ }^{8}$. En caso de conflicto de valores, una intuición valorativa intrínseca, un acto de preferencia ${ }^{9}$, revela la preeminencia de un valor sobre otro a través de la escala jerárquica de valores que rige en una determinada sociedad en un tiempo histórico determinado ${ }^{10}$. La

${ }^{6}$ Proyecto en el que puede percibirse la influencia de Cossio, por ejemplo, Vid. GIOJA, Ambrosio L., «La arquitectónica del conocimiento jurídico» (Monografía de adscripción a la cátedra de filosofía del derecho en la Universidad Nacional de La Plata-1944) en Ideas para una filosofía del derecho. Buenos Aires, Sucesión de Ambrosio L. Gioja, compilación y prólogo de Ricardo Entelman, Buenos Aires, 1973, pp. 48-63, (en adelante Ideas...).

${ }^{7}$ Algunos autores consideran que el ejercicio de la facultad de valorar resulta inescindible del trato con objetos o seres humanos. Esta opinión no excluye al conocimiento de la valoración: «... la theoria, en medida no menor que la praxis, involucra siempre alguna aestimatio»; Cfr. MALIANDI, Ricardo; «Los tres niveles de la valoración moral» en Cultura y conflicto. Buenos Aires, Biblos, 1984, pág. 67.

${ }^{8}$ Cfr. GIOJA, Ambrosio L., «La evidencia como criterio y los tres tipos de valoración» en Ideas...; op. cit., tomo II, pp. 57-62. Conferencia pronunciada en el ciclo de Integración universitaria en el departamento de Graduados de la Facultad de Derecho y Ciencias Sociales de la UBA (1962) sobre el tema Ética y vida humana - El problema de la conducta.

${ }^{9}$ En lo referente al acto de preferencia, Gioja sigue la posición que sobre esta categoría establece F. Brentano. Vid. BRENTANO, Franz; Von Ursprung sittlicher Erkenntnis. Hamburg, Felix Meiner, 1955. Para aquellos pensadores que desarrollaron la denominada «ética material de los valores» la noción de preferencia es central. Esta noción conforma el criterio para reconocer lo moralmente bueno como la coincidencia entre el valor intentado y el valor preferido. Vid. HARTMANN, Nicolai; Der Aufbau der realen Welt. Berlin, Gruyter, 1940.

${ }^{10}$ A diferencia de Max Scheler, Gioja desarrolla una posición subjetivista respecto de los valores y relativista en lo concerniente a su validez temporal y espacial. Vid. SCHELER, Max; Der Formalismus in der Ethik und die materiale Wertethik. 5e. aufl., Bern, Francke Verlag, 1966. 
norma se reduce en última instancia a la tarea de determinar la expresión de los distintos valores de una sociedad.

El análisis del derecho, entonces, debe comenzar por la expresión del derecho en la vida cotidiana de una comunidad y sus órganos, es decir, por aquellas valoraciones de conducta realizadas sobre actos coercitivos que fueron aceptadas por ese grupo humano. Esta instancia, previa a todo enfoque científico, registra los valores que serán neutralizados y objetivados mediante una abstracción ideatoria, que los transforma en objetos de una ciencia jurídica. Esta operación ${ }^{11}$ definida a partir de la norma fundante construye epistemológicamente su objeto definiendo el estatuto y el carácter de la ciencia jurídica en cuestión. Esta Grundnorm permite operar el pasaje en virtud de constituirse en presupuesto gnoseológico de dicha ciencia ${ }^{12}$.

El objeto de la ciencia del derecho, aunque parte del derecho tal como se manifiesta en la vida cotidiana, se diferencia claramente de él: derecho precientífico y derecho científico $^{13}$ nunca llegan a confundirse. Dentro de este último se encuentran la ciencia política, la dogmática jurídica, la sociología y la psicología jurídicas.

La categoría de derecho precientífico resulta ser una de las categorías fundamentales de esta metodología propuesta para una ciencia jurídica, y puede ser considerada de gran relevancia respecto de los debates más actuales de la iusfilosofía.

Esta noción conforma la plataforma teórica de una ciencia del derecho que se distingue por obtener su objeto del mundo de la experiencia cotidiana. Esta ciencia opera a través de la abstracción o idealización de las formas que reviste su objeto en la práctica social, formas que, según ya vimos, están constituidas por aquellas valoraciones sobre actos coercitivos que rigen la vida cotidiana de una comunidad.

Como es posible observar, el modelo de ciencia social propuesto por Gioja adquiere un carácter netamente comprensivo. El derecho precientífico debe constituirse a partir de valoraciones aprehendidas a través de la comprensión de expresiones significativas ${ }^{14}$. Éstas permiten fijar la significación jurídica que se les atribuye a determinadas conductas en una sociedad. Esta metodología abre el camino para el desarrollo de una reconstrucción de la perspectiva interna de los actores en una sociedad y para una técnica que permita interpretar la significación, es decir, una hermenéutica.

\footnotetext{
${ }^{11}$ Pasaje del derecho precientífico a derecho científico, es decir, la constitución de la cientificidad.

${ }^{12}$ Para el estudio de la norma fundante básica como presupuesto lógico-trascendental, vid. KELSEN, Hans, Reine Rechtslehre. Wien, Deuticke Verlag, 1967.

${ }^{13}$ Gioja desarrolla por primera vez esta distinción en el año 1957.

${ }^{14}$ Expresiones que son establecidas por legisladores y jueces.
} 
A su vez, la significación antes mencionada expresa una valoración directa de una comunidad respecto de una norma positiva. Esta perspectiva introduce un problema que tiene múltiples derivaciones en la obra de Gioja: la legitimación.

Sobre este punto, nuestro autor coincide con Max Weber en que una norma jurídica que carezca del consenso valorativo de la sociedad, con seguridad, no logrará generar obediencia en la población, en última instancia, ni siquiera en los jueces.

De este modo, se destaca que el planteamiento ontológico de los problemas jurídicos exhibido en su obra difiere de las teorías iusfilosóficas diseñadas en las matrices del positivismo lógico o del linguistic analysis ${ }^{15}$ que llevaron adelante la mayor parte de sus discípulos y colaboradores ${ }^{16}$ en el Instituto de Filosofía del Derecho ${ }^{17}$ que había comenzado a funcionar con C. Cossio.

\section{Axiología democrática}

A. Gioja analiza el problema de la democracia del mismo modo que otros problemas de la filosofía del derecho, de la ética y de la política, es decir, desde una perspectiva axiológica.

El tratamiento del concepto de democracia no escapa a esta regla general de su concepción iusfilosófica. En consecuencia, democracia, para nuestro autor, es una cuestión de valores, un problema valorativo.

Gioja desarrolla este tema en un texto titulado Algunas reflexiones sobre la democracia, su significado y su posible defensa ${ }^{18}$, en el que sostiene que la democracia es el «fundamento axiológico sobre el cual aquellos otros ideales precisan apoyarse para poder ser tenidos ellos mismos como tales ideales ${ }^{19}$. Desde luego, una vez propuesto el sistema democrático en tanto

\footnotetext{
${ }^{15}$ A pesar de una primera impresión, cabe aclarar que Gioja experimenta a lo largo de su carrera académica una profunda evolución teórica que lo acercará a posiciones de este tipo. Por influencia de sus discípulos y colaboradores comienza a interesarse por la filosofía analítica. De hecho, escribe uno de los primeros trabajos de iusfilosofía analítica en Argentina: El postulado jurídico de la prohibición. Buenos Aires, Valerio Abeledo, 1954. La trayectoria de Gioja comienza con la obra de C. Cossio, de quien era discípulo destacado.

${ }^{16}$ Entre ellos, puede contarse a Carlos Alchourrón, Jorge Bacqué, Genaro Carrió, Martín Farrell, Ricardo Guibourg, Antonio Martino, Eduardo Rabossi, Roberto Vernengo, etc.

${ }^{17}$ Dicho instituto constituyó uno de los primeros centros de estudios e investigaciones jurídicas y sociales en Argentina.

${ }^{18}$ Cfr. GIOJA, Ambrosio L., Ideas...; op. cit., tomo II, pp. 248 - 254. Este texto aparece en la compilación, sin ninguna aclaración de fecha de realización, ni carácter (artículo, conferencia, clase, etc.). Presumiblemente sea un texto tomado de una clase dictada en la Facultad de Derecho y Ciencias Sociales de la Universidad de Buenos Aires. En él, Gioja estudia el problema de la democracia en relación al federalismo.

${ }^{19}$ Cfr. GIOJA, Ambrosio L., «Algunas reflexiones sobre la democracia, su significado y su posible defensa» en Ideas...; op. cit., tomo II, pág. 249.
} 
ideal real, todo aquello que apunte a su realización más perfecta deviene también en un ideal real, en consecuencia, libertades sociales, federalismo y solidaridad social son propuestas como tales.

Sin embargo, el contenido objetivo de la democracia, para nuestro autor, está determinado por la noción de libertad. La democracia como orden social no es más que la transformación del sentimiento humano de autodeterminación. Esta transformación tiene la forma de una restricción. El hombre en sociedad no puede determinarse siempre de acuerdo a su propio querer, debe sujetarse a normas sociales. Por lo tanto, una primera acepción de libertad es la de regular con normas jurídicas el hacer humano, prohibiendo a otros ciertas conductas $^{20}$. Este concepto de libertad positiva ${ }^{21}$ acerca dicha categoría a la noción de justicia. En efecto, según este planteo, libertad y justicia remiten siempre al mismo problema: la valoración.

En el caso de la libertad y la justicia, ambas resultan de un proceso valorativo que tiene su objetividad apoyada en el hábito valorativo del grupo social del que emana la normativa. En otras palabras, Gioja rechaza nuevamente las posiciones objetivistas a la hora de pensar la libertad y la justicia. De acuerdo a su posición, los valores siempre tienen un carácter «para mí», es decir, solamente válidos para mi «querer». Sin embargo, no se descarta la posibilidad de asignar fundamento objetivo a la valoración. En este sentido, dicho fundamento no puede radicar nunca en la objetividad de la conciencia ${ }^{22}$, o en algún sujeto individual o trascendental. Por lo contrario, se afirma que «... la objetividad de los valores y de la preferencia parecieran tener su fundamento en la intersubjetividad...» ${ }^{23}$. Más adelante refuerza esta idea al sostener que «... la existencia de un derecho positivo implica la existencia

${ }^{20}$ Gioja desarrolla esta idea en una conferencia pronunciada en septiembre de 1956 titulada Libertad y justicia. Cfr. GIOJA, Ambrosio L., Ideas...; op. cit., tomo II, pág. 226.

${ }^{21}$ Para el análisis de las nociones de libertad positiva y negativa, vid. BERLIN, Isaiah; «Two Concepts of Liberty» en del mismo autor, Four Essays on Liberty. Oxford, Clarendon Press, 1969, pp. 118-172.

${ }^{22}$ Sobre el problema del fundamento objetivo de la valoración y su relación con la objetividad de la conciencia, Gioja muestra un cambio profundo respecto de sus primeros trabajos. En ellos, consideraba al contenido objetivo de conciencia como centro de despliegue teórico de toda problematización de la experiencia a fin de desentrañar sus principios fundantes. En este aspecto, su tesis doctoral, titulada «Kant y el derecho. Algunas ideas sobre Kant y la fundamentación metafísica del derecho» (en Ideas...; op. cit., Tomo I, sección 1, pp. 23-45) sintetiza la particular recepción que realiza de la obra kantiana en sus estudios juveniles, sirviendo a la vez para señalar el grado de evolución posterior de su trabajo. Sobre el problema de la conciencia en los primeros escritos de Gioja, Vid. FONDEVILA, Gustavo; «El kantismo jurídico en los escritos juveniles de A. Gioja», ponencia presentada en el VIII Congreso Nacional de Filosofía y IV Congreso de la Asociación Filosófica de la República Argentina, Mar del Plata, diciembre de 1995.

${ }^{23}$ Cfr. GIOJA, A., «La evidencia como criterio y los tres tipos de valoración», en Ideas..., op. cit., tomo 2 , sección II, pág. 72 . 
de una valoración objetiva directa del pueblo en favor de la norma positiva cuando se enfrenta con otro tipo de valoración.... ${ }^{24}$.

En este desarrollo, a la subjetividad perceptiva del valor se contrapone la objetividad lograda mediante la intersubjetividad de esa percepción ${ }^{25}$. Esta intersubjetividad no solamente es el reaseguro teórico de la objetividad de los valores sociales ${ }^{26}$ sino también la única solución mediadora posible en el surgimiento de conflictos de valores que los actos de preferencia no logren resolver (por ejemplo, en el enfrentamiento de grupos sociales con registros valorativos diferentes y contrapuestos). Los valores de un segmento social pueden significar la negación de los valores de otro grupo, o bien la negación del grupo mismo que encama esos valores.

La intersubjetividad se construye, en el esquema teórico de Gioja, a través de la discusión entre los distintos actores sociales en juego ${ }^{27}$. Ésta sirve para dirimir los enfrentamientos a través de una transacción valorativa ${ }^{28}$ entre los grupos en pugna que alcanzan de este modo un determinado consenso sobre el asunto en cuestión. Esta transacción social mediada por un acto de habla tiene una impronta institucional decisiva a la hora de obligar a cada una de las partes en relación con la otra. Por otra parte, resulta imposible alcanzar ningún consenso sobre la base del desconocimiento o exclusión de uno de los términos del conflicto en favor de otro.

De cara a la conflictividad, nuestro autor apela desde la filosofía práctica al carácter pragmático de la comunicación para establecer un principio de carácter prescriptivo. Este principio tiene por delante una labor de fundamentación que sólo puede realizar no a partir de su contenido sino por estar

${ }^{24}$ Cfr. GIOJA, A., «La evidencia como criterio y los tres tipos de valoración», en Ideas..., op. cit., tomo 2, sección II, pág. 72.

25 Para analizar el problema de discusión como mediación de la intersubjetividad, vid. HABERMAS, Jürgen, Theorie des kommunikativen Handelns. Frankfurt am Main, Suhrkamp Verlag, 1981, I, II.

${ }^{26}$ De este modo, la posición de Gioja no cae en el relativismo axiológico absoluto. Su posición subjetivista no significa que los valores no posean ninguna posibilidad de objetividad. Por el contrario, a la irracionalidad del relativismo absoluto, Gioja le opone la objetividad racional obtenida en una sociedad mediante la discusión. Dicha objetividad tendrá validez relativa (históricamente, por ejemplo).

${ }^{27}$ M. Mols señala que la formación de consenso a través del diálogo tiene una gran capacidad de integración respecto a las capas y grupos sociales. Este consenso provoca menor polarización social que las alternativas «corporativo-tecnocráticas» que desarrollan como punto de partida percepciones de amenaza. Cfr. MOLS, Manfred; «La Argentina: el difícil camino hacia la normalidad democrática» en La nueva democracia argentina. Buenos Aires, Sudamericana, 1988, cap. 1, pág. 11.

${ }^{28}$ Esta categoría señala el proceso por el cual a través de la discusión, un grupo decide abandonar la consecución de un determinado ideal, o antepone un ideal ajeno a uno propio, o pospone la realización de un valor, o le impone un valor propio a un grupo para el cual dicho valor era ajeno. 
necesariamente presupuesto en el ámbito pragmático que concierne a toda argumentación. La dimensión trascendental del lenguaje permite a Gioja eludir toda interpretación metafísica $^{29}$ que sometería a dicho principio al rigor del Trilema de Münchhausen ${ }^{30}$.

Este principio sirve de metanorma para fundamentar el resto de las normas aplicadas a circunstancias específicas de conflicto. Es una prescripción que establece la normativa de procedimientos $^{31}$ a poner en juego en la resolución de enfrentamientos. El principio determina que esta normativa debe ser consensuada a través de la discusión entre los distintos grupos sociales en pugna que sean comprendidos por los alcances de la misma. Esta disposición alcanza el nivel de fundamento al encontrarse siempre incluida y presupuesta en toda situación argumentativa ${ }^{32}$.

Con este desarrollo, Gioja rompe definitivamente los límites de la ética material de los valores de la que parte en su análisis.

Según algunos autores, esta filosofía práctica expresa una ética discursiva que «porte de relieve la irrebasabilidad (Nichthintergehbarkeit) de su principio fundamental.... ${ }^{33} \sin$ lograr destacar la Nichthintergehbarkeit de lo conflictivo.

Según la concepción de Gioja, la propia racionalidad del sistema democrático radica en la racionalización de los procesos conflictivos a través de la discusión sobre la preeminencia de determinados valores considerados muy valiosos para uno de los contendientes y menos valiosos para la consideración del otro. Sobre este punto, Gioja afirma que «... el fundamento racional último de la autonomía de la voluntad en el derecho privado y de la democracia representativa de partidos políticos, en el derecho constitucional,

\footnotetext{
${ }^{29}$ Del mismo modo, la interpretación pragmática del principio en cuestión le permite abandonar una lectura semántica.

${ }^{30}$ Este Trilema fue formulado por Hans Albert y establece que toda respuesta prescriptiva a la clásica pregunta ética ¿por qué debo? debe tolerar que se pregunte infinitamente por qué, o bien puede responder con algún «deber» sin una fundamentación adecuada, o también solucionar imperativamente el problema situando la fundamentación en sí misma. Cualquiera de estas posibilidades carece de una fundamentación racional de la solución a este viejo problema. Este desarrollo constituye una de las principales críticas que Albert dirige a la obra de K.O.Apel. Cfr. ALBERT, Hans, Traktat über kritische Vernunft. Tübingen, Mohr, 1980, pp. 11 ss., 24 ss., 129 ss., 173 ss.

${ }^{31}$ El desarrollo del carácter procedimental de este principio ha sido estudiado por Maliandi. Vid. MALIANDI, Ricardo, «Convergencia ética» en Cuadernos de ética, $\mathrm{n}^{\circ}$ 14, Buenos Aires, diciembre de 1992, pp. 77 ss.

${ }^{32}$ Resulta imposible negarla, ni fundamentarla en el sentido tradicional.

${ }^{33}$ Cfr. MALIANDI, Ricardo, «Convergencia ética» en Cuadernos de ética, op. cit., pág. 78. Según este autor, la complementariedad de la razón debe situarse en la contraposición de la dimensión fundamentadora de la razón que descubre los principios, y la dimensión crítica que descubre sus interrelaciones conflictivas.
} 
se encuentra precisamente en la necesidad de discusión y transacción cuando se quieren conseguir ciertos valores $\rangle^{34}$. Es interesante advertir que esta afirmación propone situar en el potencial argumentativo de los sujetos el ámbito donde puede rastrearse la fundamentación racional de la autonomía de la voluntad y de los derechos de participación política. El carácter de esta propuesta coloca a Gioja en un terreno teórico que ciertas corrientes de la ética y la filosofía jurídica y política van a transformar en el centro de la discusión filosófica bastantes años más tarde ${ }^{35}$.

La función de la discusión es aclarar «... la trama de valores como medios y valores como fin ${ }^{36}$ de los grupos en pugna. Entonces, la transacción permite «... la elevación de los intereses a normas preferenciales de valores objetivos $\rangle^{37}$.

A partir del reconocimiento de las estructuras conflictivas de la sociedad, Gioja establece la exigencia de consenso a través de la discusión y transacción. Sobre este punto, es posible observar en la actualidad que frente a una necesidad cada vez mayor de formación de consenso en las interacciones sociales conflictivas se han acentuado proporcionalmente las dificultades para alcanzar dicho consenso. Según algunos autores ${ }^{38}$, esta paradoja del consenso constituye una de las características principales de las sociedades modernas.

Este consenso se representa en las instituciones políticas del sistema democrático, por ejemplo, los partidos políticos ${ }^{39}$, el parlamento, etc. El sistema democrático no significa la eliminación de los conflictos sociales pero sí la posibilidad de su justa solución. El parlamentarismo, donde rige el

${ }^{34} \mathrm{Cfr}$. GIOJA, A., «La evidencia como criterio y los tres tipos de valoración», en Ideas..., op. cit., tomo 2, sección II, pág. 73.

${ }^{35}$ Aquí se hace referencia al desarrollo contemporáneo de las éticas discursivas. Vid. APEL, Karl-Otto, Diskurs und Verantwortung. Frankfurt, Suhrkamp Verlag, 1988. Vid. HABERMAS; Jürgen, Moralbewusstsein und kommunikatives Handeln. Frankfurt, Subrkamp Verlag, 1983.

${ }^{36}$ Cfr. GIOJA, A., «La evidencia como criterio y los tres tipos de valoración», en Ideas..., op. cit., tomo 2, sección II, pág. 73.

${ }^{37}$ Cfr. GIOJA, A., «La evidencia como criterio y los tres tipos de valoración», en Ideas..., op. cit., tomo 2 , sección II, pág. 74.

${ }^{38}$ Vid. GIEGEL, Hans-Joachim (Compil.), Kommunikation und Konsens in modernen Gessellschaften. Frankfurt am Main, Suhrkamp Verlag, 1992. En la primera parte de este libro, el artículo de Giegel establece tres formas de consenso: a) consenso de fondo (experiencias compartidas por todos), b) consenso de resultado (consenso sobre los resultados pero no sobre las fundamentaciones), y c) consenso de argumentación (acuerdo sobre los resultados y sobre la fundamentación).

${ }^{39}$ Para Gioja, los partidos políticos cumplen un papel esencial, integrando de manera uniforme los intereses del grupo social que representan. 
principio de la voluntad de la mayoría, es una clara muestra de construcción de objetividad ${ }^{40}$. Dicha objetividad basada en la discusión y transacción de valores deviene en el fundamento de la valoración normativa y en última instancia de la libertad y de la justicia. Valoraciones que Gioja ha identificado anteriormente con la democracia. Al igual que los pensadores de la modernidad iluminista ${ }^{41}$, este autor cree que la razón se realiza en las instituciones del sistema democrático.

De allí, su severa advertencia respecto de aquellos factores que pueden interferir negativamente en la formación de intersubjetividad y, por ende, impedir la realización de la libertad. En este punto, según nuestra opinión, el desarrollo sufre una seria descompensación teórica. Dado que su método descarta la neutralidad valorativa, Gioja se ve implicado en los valores de su objeto de estudio. En este caso, se considera disvaliosa la propaganda y la autoridad política para la conformación de intersubjetividad ${ }^{42}$.

Esta descompensación resulta natural en un planteo que funda la «objetividad» de los valores en la intersubjetividad, pero a la vez, sustenta sus propios valores. La aparición de la subjetividad parece inevitable, dado que la intersubjetividad está compuesta de subjetividades, entre ellas las del observador. Una solución radica en la identificación de los propios valores con los que la sociedad aprobaría «si se encontrara libre de distorsiones»" En realidad, esto genera una serie de problemas más complejos aún: la identificación de las distorsiones ${ }^{44}, ¿$ cómo distinguir en este caso,

${ }^{40}$ El principio de la voluntad de la mayoría es, para nuestro autor, lo más cercano a la objetividad. Kelsen considera que este principio es muy adecuado para eludir el predominio de una clase. A su vez, señala que el principio de la mayoría cualificada conforma una importante realización de la libertad, dado que puede significar una decisiva tendencia a la unanimidad. Ante todo, dicho principio constituye sociológicamente una fuerza de integración social. Respecto de este concepto, vid. KELSEN, Hans, Wesen una Wert der Demokratie. Tübingen, J.C.B. Mohr, 1929, VI.

${ }^{41}$ Por ejemplo, I. Kant. Vid. KANT, Inmanuel, «Idee zu einer aligemeinen Geschichte in weltbürgerlicher Absicht» en Kain Werke; Wiesbaden, Insel Verlag, 1960, Band XI-XII. 33-53. Hegel, por ejemplo, sitúa la realización de la razón en el Estado. Vid. HEGEL, George W. F., «Grundlinien der Philosophie des Rechts oder Naturrecht und Staatswissenschaft im Grundisse» en Hegel Werke. Frankfurt am Main, Suhrkamp Verlag, 1970, Band VII. 1951.

${ }^{42}$ Vid. WEBER, Max, Gesammelte Aufsätze zur Wissenschaftslehre. Tübingen, Winckelmann,

${ }^{43}$ En definitiva, ésta es la posición de autores como Habermas, quien cree que la ideología es una situación de hecho, una distorsión de la situación ideal de libre comunicación. Esta distorsión es el efecto de una coacción fáctica y de una legitimación que fundamenta esta situación. Vid. HABERMAS, J. y LUHMANN, N., Theorie der Gesellschaft oder Sozialiechnologie? Frankfurt am Main, Suhrkamp Verlag, 1971, pág. 119 ss.

${ }^{44}$ Esto puede remontarse al viejo problema de la ideología entendida como alteración de la realidad. R. Entelman sostiene en el prólogo a Ideas..., op. cit., tomo I, pp. 21-22, que las reflexiones de Gioja sobre la verdadera naturaleza del objeto jurídico sirven para desentrañar 
propaganda de información, liderazgo de libre iniciativa y libre aceptación? ${ }^{45}$

$\mathrm{Al}$ respecto, Gioja señala que la propaganda ${ }^{46}$ «sirve para nuclear artificiosamente una intersubjetividad y para crear autoridad $\rangle^{47}$. Entendida la autoridad como aquel hombre que se instituye en paradigma. Dicho hombre «puede constituir objetividades axiológicas, no sólo a través de sus valoraciones, sino también a través de sus conductas, aunque éstas no se funden en una valoración consciente» ${ }^{48}$. Gioja advierte que en esta naturaleza de autoridad axiológica radica la explicación de algunos mecanismos de control social ${ }^{49}$. No toda autoridad axiológica implica una amenaza para la libertad. Obviamente, la crítica está dirigida a un tipo especial de autoridad política: la jefatura ${ }^{50}$. El mandato de la jefatura no se realiza por medio de la persuasión racional sino a través del influjo emocional y la entrega afectiva. Si bien, reconoce que la propaganda puede servir como factor de respeto a la ley, observa que éste no es más que «la simple repetición de actos exteriores que generan acostumbramiento a los mandatos coincidentes con el contenido de aquella» ${ }^{51}$. La creencia (Glauben) de los individuos desplaza a las motivaciones racionales. La acción consensual (Einverständnishandel) se guía ahora exclusivamente por expectativas irracionales. Gioja, siguiendo a $\mathrm{Weber}^{52}$, establece una relación lógica entre las razones de obediencia de los individuos a un sistema político y la validez objetiva de esas motivaciones como fundamentos de legitimidad de ese sistema.

el carácter ideológico de ese objeto y del discurso que lo describe. Para el problema de la ideología vid. GEIGER, Theodor, Ideologie und Wahrheit. Eine soziologische Kritik des Denkens. Stuttgart-Wien, Humboldt Verlag, 1953.

${ }^{45}$ Sobre este asunto, Gioja tenía dos antimodelos: el de Perón y el de Onganía.

${ }^{46}$ Este término se encuentra desactualizado por completo. Hoy se hablaría de medios de comunicación y formación de opinión.

${ }^{47}$ Cfr. GIOJA, A., «La evidencia como criterio y los tres tipos de valoración», en Ideas..., op. cit., tomo 2 , sección II, pág. 61 .

${ }^{48}$ Cfr. GIOJA, A., «La evidencia como criterio y los tres tipos de valoración», en Ideas..., op. cit., tomo 2 , sección II, pág. 61.

${ }^{49}$ Gioja admite que la intersubjetividad y la autoridad conforman «la evidencia del valor, son los elementos constitutivos de su intuición». Cfr. GIOJA, A., «La evidencia como criterio y los tres tipos de valoración», en Ideas..., op. cit., tomo 2, sección II, pág. 61.

${ }^{50}$ En otros textos, se puede observar que está pensando en un movimiento particular de nuestra historia política: el peronismo. Cfr. GIOJA, A., «Algunas reflexiones sobre la democracia, su significado y su posible defensa», en Ideas..., op. cit. pág. 253. La Constitución de 1949 que expresaba un constitucionalismo puesto al servicio de la personalización del poder parece corroborar la opinión de Gioja. Cfr. BOTANA, Natalio, «Tradiciones e instituciones en la democracia argentina», en $L a$ nueva democracia argentina, op. cit., pág. 36.

${ }^{51}$ Cfr. GIOJA, A., «El respeto a la ley», en Ideas..., op. cit., tomo 2, sección II, pág. 237. Conferencia dictada en 1965.

${ }^{52}$ Vid. WEBER, Max, Staatsoziologie. Berlín, Winckelmann, 1966. También del mismo autor, vid. Wirtschaft und Gessellschaft. Tübingen, Winckelmann, 1972. 
El estadista colabora haciendo surgir los valores del grupo social de pertenencia, al calificar axiológicamente situaciones políticas nuevas. En cambio, la jefatura refuerza el respeto a la ley a través de la autoridad y el mandato, pero dicho refuerzo motivador de la voluntad resulta viciado de irracionalidad. En otras palabras, el mecanismo impuesto aparece así como irracional. Gioja está pensando en un gran partido puesto al servicio de un líder carismático que se apodera del poder y lo ejerce en forma irrestricta, llegando a identificar los intereses del partido con los intereses personales del líder para identificar a su vez los intereses del partido con los del sistema político.

Esta concepción permite justificar que la democracia pueda generar mecanismos de defensa contra expresiones, actitudes y propagandas que contribuyan a formar valoraciones contrarias al sistema democrático. En otras palabras, el sistema democrático puede apelar a regulaciones no democráticas.

Con este desarrollo, el planteo de la primacía de la intersubjetividad, de clara vocación democrática ${ }^{53}$, comienza a empañarse con elementos de la realidad política de nuestro país que Gioja se niega a desatender ${ }^{54}$. En apariencia, la discusión, transacción y búsqueda de consenso pueden interrumpirse llegados a un punto percibido como inaccesible a la racionalidad. La argumentación práctica situacional se ve desplazada por un acto de voluntad que sostiene una decisión última que escapa a la razón ${ }^{55}$.

Puede darse el caso de que «un pueblo que acepta la democracia y que valora con gran peso la propiedad privada se enfrenta con problemas de propaganda, por ejemplo, en favor de la propiedad estatal ${ }^{56}$. En este caso no hay

${ }^{53}$ Esto ya fue señalado por Atienza. Cfr. ATIENZA, Manuel; op. cit., Cap. 2, pág. 86. «Como es fácil de ver, por debajo de esta concepción de los valores, late una ideología democrática que Gioja ha asumido alguna vez expresamente...».

${ }^{54}$ Ya al comienzo del texto El respeto a la ley, que citamos anteriormente, Gioja se queja de que los argentinos no puedan hablar de política sin recaer en la discusión de las ventajas y desventajas de un cambio de gobierno a través de un golpe de estado. A pesar de esto, en el ya mencionado Algunas reflexiones sobre la democracia, su significado y su posible defensa, Gioja prefiere el golpe de estado encamado por un estadista al irracionalismo de la jefatura política. Según nos refiere personalmente el Dr. Ricardo Guibourg, Gioja tenía otro modelo por referencia histórica: la revolución del '55. Nuestro autor, hombre de su época, era un «gorila democrático». En esos momentos de nuestra historia, era muy común en ciertos sectores políticos sostener el mito de la libre elección popular (Leonardi y Aramburu).

${ }^{55}$ En este aspecto, Gioja deja de lado la razón intersubjetiva para recalar en posiciones propias del decisionismo axiológico de Max Weber. En las ciencias sociales, por ejemplo, la prioridad de un determinado valor no se encuentra determinada por la razón sino por una decisión de la voluntad. Vid. WEBER, Max, Gesammelte Aufsätze zur Wissenschaftslehre. Tühingen, Winckelmann, 1951.

${ }^{56}$ Aquí, resulta obvio pensar que está refiriéndose al peronismo. Recordemos que Gioja mantenía un contacto fluido con el General Aramburu que alcanzó el poder de la mano de la célebre «Revolución libertadora». En este sentido, es importante resaltar que Cossio había sido 
cuestión en contra de la democracia si se prohíbe esta propaganda» ${ }^{57}$. No satisfecho aún con esta precaución aclara más adelante que la desaparición de la propiedad privada «no sólo ataca el valor directo concreto, sino que puede pensarse como causante, como productora, de los procedimientos para eliminar la democracia ${ }^{58}$.

De este modo, no le resulta difícil llegar a la conclusión de que «impedir que otros hombres, con ideologías contrarias a las señaladas, concurran con su voluntad, sea para elegir representantes, sea para dictar normas en forma directa, o limitarles su poder de crítica, no contradice, de manera alguna, dicha idea democrática $)^{59}$. Las ideologías señaladas en el parágrafo hacen referencia al principio de la mayoría y la libertad de crítica. Curiosamente, los soportes de la intersubjetividad, la discusión y la transacción, pueden ser eliminados en defensa de la democracia. Esta misma puede verse anulada en su beneficio.

No se encuentra en su obra un análisis profundo de las peligrosas consecuencias prácticas de estas conclusiones teóricas. La preocupación principal parece residir en otro problema: en la defensa a ultranza, aún mediante un golpe de Estado, de valoraciones propias de un determinado grupo social. Valoraciones que Gioja identifica sine qua non con los valores fundantes del sistema democrático. De este modo, se incurre en una forma de falacia naturalista muy común en las ciencias sociales: la identificación entre la esfera del ser y la del deber ser. La propiedad privada deja de ser un valor pasible de ser sometido a la discusión, es decir, a la crítica racional de valores que esta significa, para transformarse en una normativa ${ }^{60}$. Este pasaje

destituido por sus relaciones con el peronismo. Ya Soler acusaba a la egología de subjetivismo axiológico y, según él, de servir a intereses totalitarios. Vid. SOLER, Sebastián, «Los valores jurídicos», en Revista Jurídica de Córdoba, año 1, nº 2, 1947. Según nos refiere personalmente el Dr. Sandler, Gioja encarnaba una oposición al peronismo diametralmente opuesta a la de Soler. Sandler distingue entre una crítica liberal (Gioja) y una crítica conservadora (Soler). Este último terminaría siendo funcionario del gobierno del Proceso de Reorganización Nacional durante el mandato de Jorge Rafael Videla.

${ }^{57}$ Cfr. GIOJA, A., «Algunas reflexiones sobre la democracia, su significado y su posible defensa», en Ideas..., op. cit., tomo II, pág. 253.

${ }^{58} \mathrm{Cfr}$. GIOJA, A., «Algunas reflexiones sobre la democracia, su significado y su posible defensa», en Ideas..., op. cit., Tomo II, pág 253. En este aspecto, quizás resulte importante destacar que Gioja era un importante terrateniente.

${ }^{59} \mathrm{Cfr}$. GIOJA, A., «Algunas reflexiones sobre la democracia, su significado y su posible defensa», en Ideas..., op. cit., tomo II, pp. 253-254. Atienza considera acertadamente, según creemos, que este texto fundamenta y justifica «claramente la proscripción de que fue objeto el peronismo en la etapa posterior a la Revolución Libertadora». Cfr. ATIENZA, Manuel; op. cit., pág. 87.

${ }^{60} \mathrm{Si}$ entendemos al derecho en tanto ciencia social, la discusión sobre valores es una de sus funciones prioritarias. La previsibilidad de las consecuencias de un determinado valor permite establecer su coherencia o incoherencia. 
del terreno práctico al normativo tiene consecuencias políticas que gravitan restrictivamente sobre la libertad de los individuos que viven en un sistema democrático. La existencia de valores apodícticos cierra el camino de la libre elección de la voluntad y por lo tanto, del pluralismo abierto de la discusión intersubjetiva. La propiedad privada deja de ser un valor para convertirse claramente en un a priori, un juicio práctico de valor que sirve para orientar y determinar la acción.

Según parece, cabe suponer que cuando la discusión no logra generar intersubjetividad sobre ciertos temas, por ejemplo, la necesidad de sostener la propiedad privada frente a la estatal, la objetividad debe lograrse mediante la violencia que significa para las instituciones democráticas un golpe de Estado. Gioja advierte que este recurso sólo puede darse $« \ldots$ en situaciones últimas y durante muy reducido trecho de tiempo, dado el constante peligro de que lo fáctico modifique la ideología... ${ }^{61}$. En realidad, dada la historia política de nuestro país, esta advertencia resulta por lo menos ingenua. Desafortunadamente, no se analiza una posibilidad que nuestra historia posterior transformó en real y que Gioja no alcanzó a vivir: una burocracia militar arrasando con los derechos y garantías de la ciudadanía, sometiendo a la sociedad civil a su propia disciplina y construyendo un sistema que bajo la oscuridad de las jerarquías y la impunidad acomete cualquier clase de acto criminal.

En definitiva, según Gioja, el problema del hombre democrático está solventado «si con el objeto de salvar el principio de la mayoría o la libertad de crítica, los restringe y aún los suprime» ${ }^{62}$.

Estas palabras señalan irrecusablemente que la perspectiva axiológica sufre una profunda torsión en la obra que nos ocupa. El planteo de la intersubjetividad y la discusión, de vasta raigambre democrática, queda absolutamente desvirtuado si se lo expone a la lisa y llana legitimación de prácticas políticas propias de un orden antidemocrático ${ }^{63}$.

${ }^{61} \mathrm{Cfr}$. GIOJA, A., «Algunas reflexiones sobre la democracia, su significado y su posible defensa», en Ideas..., op, cit., tomo II, pág. 254.

${ }^{62} \mathrm{Cfr}$. GIOJA, A., «Algunas reflexiones sobre la democracia, su significado y su posible defensa», en Ideas..., op. cit., tomo II, pág. 254.

${ }^{63}$ Según nos refiere personalmente el Dr. Ricardo Guibourg, Gioja consideraba a la democracia como una supraideología que, sin embargo, no era universal. Para alcanzar esa universalidad era lícito impedir, aunque fuera por la fuerza, el advenimiento, por ejemplo, del nacionalsocialismo de A. Hitler. Hitler y Perón se encontraban fuera de la racionalidad del sistema democrático, al igual que Onganía. Por lo contrario, no opinaba lo mismo del presidente de Chile, Salvador Allende.

DOXA 21-I (1998) 